\title{
Exploration of the Application of Door and Window Art in Ming and Qing Dynasties in Modern Jewelry
}

\author{
Chuyi Wang, Wenjing Min \\ Institute of Resources, Environment and Jewelry, Jiangxi Applied Technology Vocational College, Gan Zhou, China \\ Email: 501307283@qq.com
}

How to cite this paper: Wang, C. Y., \& Min, W. J. (2022). Exploration of the Application of Door and Window Art in Ming and Qing Dynasties in Modern Jewelry. Art and Design Review, 10, 47-55.

https://doi.org/10.4236/adr.2022.101005

Received: December 19, 2021

Accepted: January 17, 2022

Published: January 20, 2022

Copyright $\odot 2022$ by author(s) and Scientific Research Publishing Inc. This work is licensed under the Creative Commons Attribution International License (CC BY 4.0).

http://creativecommons.org/licenses/by/4.0/

\section{(c) (i) Open Access}

\begin{abstract}
The architecture of the Ming and Qing Dynasties recorded the splendid ancient culture of China, and has long become a remarkable cultural heritage. Among them, the traditional doors and windows are one of the components of the traditional Chinese buildings. Doors and windows are an important part of the building. In traditional Chinese buildings, doors and windows are important components with both aesthetic and practical functions. This paper deeply discusses the art of doors and windows in the Ming and Qing Dynasties, integrates it with the modern jewelry language, and tries to give the jewelry a variety of visual senses, as well as strive to diversify the Chinese modern jewelry design field while inheriting the traditional door and window art. The paper first analyzed the artistic beauty of doors and windows in the Ming and Qing Dynasties, and studied the shape, material and process of window ornaments respectively. The application of door and window art in other art raises the problem of how door and window art should be applied in jewelry. Finally, and the inheritance, integration and development of the artistic characteristics of doors and windows of Ming and Qing Dynasties in the jewelry production process are explored.
\end{abstract}

\section{Keywords}

Ming and Qing Dynasties, Door and Window Art, Modern Jewelry Design

\section{Introduction}

"Modern jewelry design is a broad category. It contains a variety of jewelry shapes in line with modern art, modern processing industry, modern business and social environment, and is the product of the common combination of mod- 
ern material civilization, art and science" (Ren, 2011).

The traditional Chinese doors and windows art is an art carrier passed down from generation to generation by the country and the nation and with great cultural characteristics (Jiu, 2013). While having the use function, it also contains many aesthetic cultures with national characteristics. From single to rich, from plane to three-dimensional, from simple function to take into account beauty and connotation, from an element of the building to the independent expression of the design concept, it has gradually evolved into an independent decoration means. Traditional Chinese buildings can be roughly divided into two types: official and residential buildings. Official buildings were constrained by French rules and regulations, making the architectural patterns highly unified, and there were no very different intervals, reflecting the highest technical and artistic level in the country at that time; the residential houses are jointly designed by users and craftsmen, with rich architectural patterns and distinctive local characteristics, presenting the rich and colorful appearance of ancient Chinese architecture. Therefore, the integration of the Ming and Qing Dynasties doors and window art and modern jewelry design is of great practical significance.

The concept of modern jewelry design in China was also introduced from the West in the later stage, and started late. There is still a certain gap with the West. In the early stage of modern jewelry design, what we did only blindly reference and imitate, and did not integrate our advantages of rich national culture into the jewelry design. With the development of The Times, Oriental culture has also been borrowed from more and more designers. Western jewelry designers have also sought inspiration for modern jewelry from Oriental culture, which also makes us firm in the artistic wealth left by traditional Chinese culture, which requires us to understand, explore and inherit. The application of these to the jewelry design can not only add the humanistic feelings of the jewelry, meet more personalized needs, but also better inherit and carry forward the traditional Chinese culture. The author hopes to combine the combination of door and window art and jewelry design, and apply it to the jewelry after refining, streamlining and reconstructing the elements of door and window art, give jewelry the cultural connotation of traditional doors and windows, and design jewelry works with Chinese characteristics.

\section{Cultural Research of Doors and Windows Art in the Ming and Qing Dynasties}

\subsection{Historical Source Flow of the Doors and Windows}

With the emergence of the original cave houses, the original doors and windows were invented for the ventilation and lighting of the house. The doors and windows were initially integrated, considering the entrances and exits, ventilation and lighting. The form of door and window decoration develops with the development of its shape system.

The era of preserved doors and windows in China appeared in the Han Dy- 
nasty. It is not difficult to see the existing pane forms at that time, such as positive square and oblique square. In the Wei and Jin Dynasties, there are a large number of mullatoned forms of windows. The mullatoned windows not only make the indoor and outdoor transparent, but give users a panoramic view of the window indoors, but also enhance the lighting function of the window. The Sui and Tang Dynasties were a heyday of Chinese feudal society. The main hall of Foguang Temple (built in 857) and the South Zen Temple (built in 782) remain today. To the Song Dynasty, the prosperity of social economy, especially the prosperity of commodity economy, made the achievements of architectural art push the Song Dynasty to a heyday period. The window ornaments of the Song Dynasty have been focused on the decorative meaning, full of artistic atmosphere. By this time, windows have developed from simple functionality to a focus of architectural decoration as well as a carrier of expressing personal emotion. In the Ming and Qing Dynasties is the outstanding era of Chinese architectural art achievements, the rapid development of Chinese doors and windows art, show a unique personality and unprecedented glory, official building the most representative is the redbud city in Beijing, its magnificent, from the overall layout to the fine decoration, decoration patterns of doors and windows to the painting highlights the royal style. The window decorations of residential buildings are like a hundred flowers bloom, relatively simple and delicate.

\subsection{Cultural Connotation and Decorative Characteristics of Doors and Windows of Ming and Qing Dynasties}

The decorative elements of the doors and windows in the Ming and Qing Dynasties are a form of expressing the internal meaning, which is the externalization of the concept. These meanings are usually obtained by the refining and re-creation of the doors and window patterns and the meaning of the historical and cultural background of that time, which fully reflects the cultural connotation of that time. The designer expressed the aesthetic and traditional culture of the time through different methods of expression, abstracted or figuratively. From the decoration of doors and windows to the graphics, they all show the cultural connotation and meaning under the background of The Times. The meaning of these decoration mostly carries people's vision for a better life, but also reflects the cultural cultivation and aesthetic taste of doors and windows users. Therefore, although there are many kinds of doors and windows decoration, they are basically designed around the auspicious meaning, expressing people's yearning for a better life.

With the improvement of people's living standards, the improvement of craftsmen, the increase of the number of merchants and the participation of literati, the maturity of conditions in all aspects drive the art and culture of doors and windows to keep pace with The Times, and promote the art of doors and windows in the Ming and Qing Dynasties to gradually develop into a major symbol of the times.

In the process of creation, the doors and window decoration of Ming and 
Qing Dynasties not only needs to consider the beauty of the external decoration, but also needs to integrate the individual wishes of door and windows users into the decoration design. The techniques of "understanding" and "homophonic" are usually used in the creation of decorative decoration. "Understanding" is actually "symbolic meaning", which is also a design idea commonly used in door and window decoration, which is to express the appearance of a certain thought by a specific thing. "Homophonic", as the name implies, uses the same or close tone of Chinese characters to read some names similar to auspicious meanings to decorate decorative patterns.

\section{Application of Doors and Windows Art in Ming and Qing Dynasties in Modern Jewelry}

The most basic component of the doors and windows of the Ming and Qing Dynasties should be the shape. China's long culture and historical background provides rich pattern materials for modern jewelry design. We should apply the art of doors and windows to the modern jewelry design, and the most direct embodiment is that the modeling characteristics of easy doors and windows appear in the jewelry. But such applications should avoid direct replication. We need to extract traditional cultural elements and combine expression techniques, modeling means and formal beauty rules to re-create. The Ming and Qing Dynasties doors and window art should be applied in the jewelry design.

"Jewelry design is the product of the development of human civilization to a certain stage. From the early Paleolithic era, humans used leaves and birds' feathers as clothes, with the primary aesthetic thought and practical basis of jewelry design" (Wen, 2009). It is hoped that through the in-depth exploration of the door and window art of the Ming and Qing Dynasties, we can explore the coincidence point between the modern jewelry art and the door and window art of the two from the perspective of the Ming and Qing design, as well as pour fresh blood into the traditional culture. This chapter respectively from aesthetic characteristics, decoration, cultural connotation of three aspects of in-depth research, aims to broaden the jewelry design thinking, and combined with market positioning analysis of door and window art, inheriting the traditional art combined with modern jewelry design techniques and modern aesthetic needs, spiritual needs, trying to find out the Ming and Qing Dynasties window art and modern jewelry design contrast as a fit point, make jewelry has a rich sense of hierarchy. In addition, this chapter will also compare the traditional aesthetic and modern aesthetic, traditional material and modern material, traditional color and modern color, and other factors, and explore the national and cultural integration of traditional and modern jewelry design.

\subsection{The Combination of the Aesthetic Characteristics of Doors and Windows and the Jewelry Language in the Ming and Qing Dynasties}

In the jewelry design aesthetics, the formal beauty will highly summarize the 
image expressed by the design. Among them, the relationship between color and light and dark is the premise of producing all visual images. Through different levels and local and overall color collocation, it can bring completely different visual impact effects to people. At the same time, color will stimulate people's feelings and cause viewers to associate with the meaning of jewelry works. Color's psychological feeling is not fixed and will change with psychological changes. Light and shadow effect complement color brightness and complement each other. The addition of light and shadow makes color present a richer hierarchical relationship, with visual effects such as increasing spatial three-dimensional sense and elongation depth. If the combination of light and shadow and color is properly used, jewelry is visually blurred and changeable. Jewelry materials are mostly used in metals and gems, because they are photosensitive materials, the shining point of the gems and the light point of the metal can produce a visually dazzling effect. And non-photosensitive materials have light absorption, not light transmission and other characteristics, and form different visual feelings with photosensitive materials.

Through the study of the aesthetic characteristics of doors and windows, the form beauty, color beauty and artistic conception of doors and windows are reconstructed through the law of composition, the shape decoration is refined into simple jewelry language in a simple way, and use different processes and materials to create contrast and different beauty.

\subsection{Ming and Qing Dynasties Doors and Windows Modeling in the Jewelry Embodiment}

As Figure 1 shows, the most prominent feature of the door and window modeling is the complex mortise and tenon structure, which is the most primitive connection mode of the wooden process. It is also the most scientific and reasonable way that people can think of in the current era.

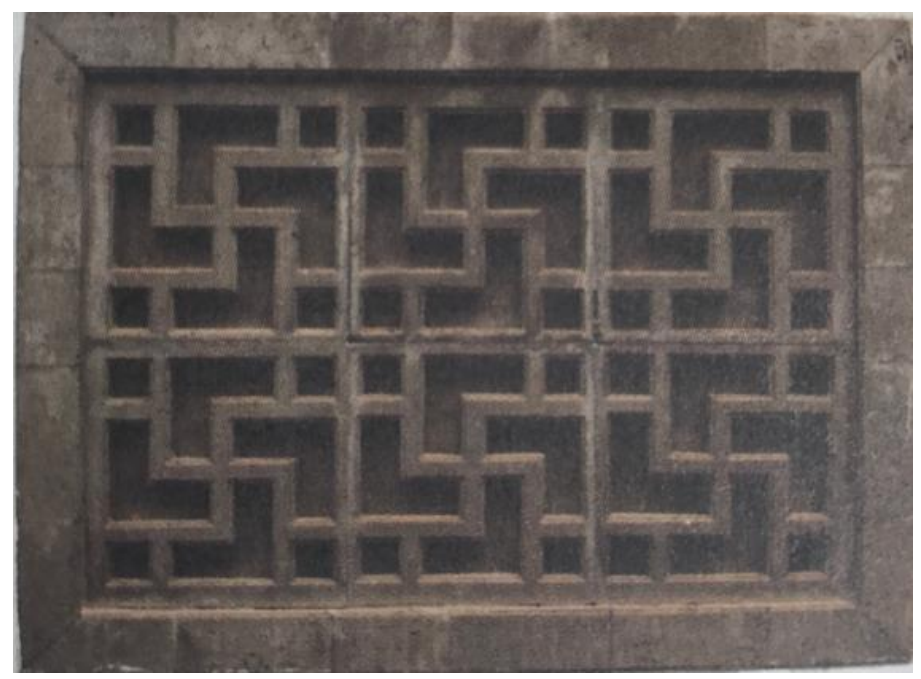

Figure 1. Door and window decoration (http://www.cang.com/trade/show-986841-2.html). 
According to the different structure and pattern characteristics of the doors and Windows, different methods will be adopted for mortise and tenon. "There are flat tenon, inclined tenon, diagonal tenon, diagonal tenon, joint tenon, single tenon, double tenon, string tenon and so on. Early rectangular pane center part of more string tenon, ice crack pane center can only use inclined tenon" ( $\mathrm{Gu}$, 2007). The extensive use of mortise and tenon process is also because it is more economical and saves material than the carving process, and has a strong stability.

Jewelry modeling leaves people with an intuitive and clear overall image. Modern jewelry modeling through the grasp of the proportion scale, symmetry and balance and rhythm, modern jewelry can effectively strengthen the artistic conception effect of doors and windows carried by modern jewelry design as Figure 2 shows. The three-dimensional visibility of the jewelry design makes the jewelry more three-dimensional in the modeling performance.

\subsection{The Ming and Qing Dynasties Doors and Windows Colors Are Reflected in the Jewelry}

Most of the doors and windows of the Ming and Qing Dynasties retained the color and texture of the wood itself, natural and fresh. Among them, the color decoration of the separate doors and windows is relatively rich. According to the overall collocation of the architecture and the social form of that time, the craftsmen can determine and practice it with their own experience. The expansion of jewelry materials strengthens the expression form of the designed theme. By combining the different materials and the different connotations of doors and windows, the two formed a certain contrast not only can wipe out a different spark, but also choose by consciously the comparison of different processes to strengthen the visual feeling of the design.

The premise of visual image generation is mainly color, through different combinations, can form a rich visual effect. For example, in Figure 3, in modern

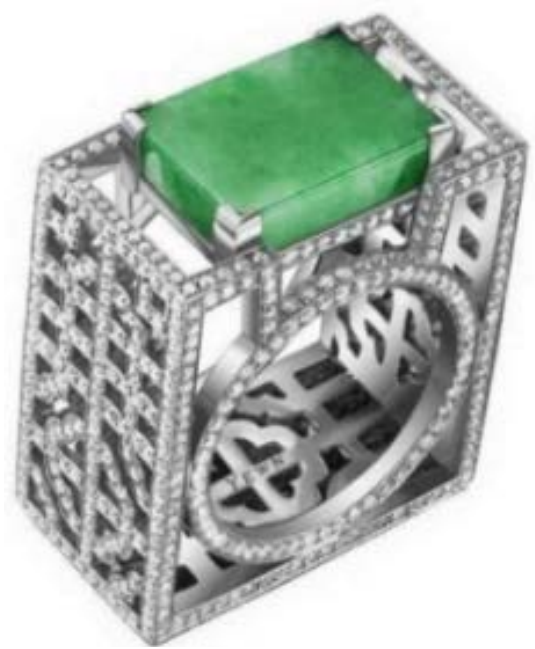

Figure 2. Modern jewelry (Yewn, 2012). 

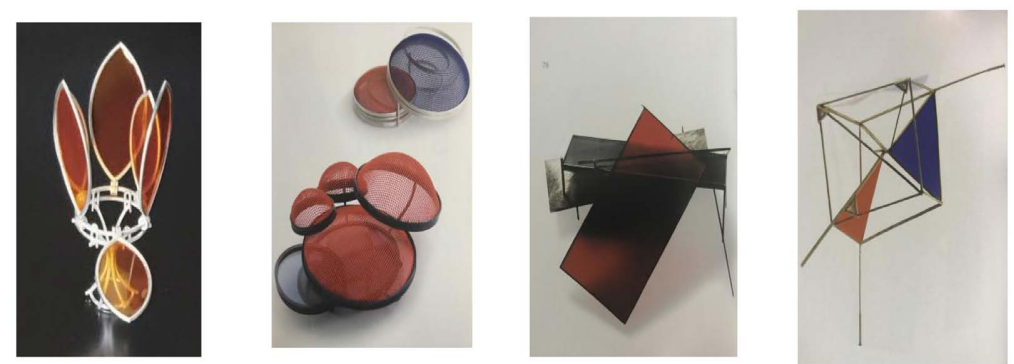

Figure 3. The embodiment of color in modern jewelry (Crafts, 2007).

jewelry, light and color are often used to form a visual impact. Therefore, the rational use of color and light and shadow is very important to create a modern sense of jewelry.

The author thinks that the combination of the color of doors and window art and modern jewelry can be expressed by the use of different materials and techniques. Based on the basis of doors and windows modelling, the color of rich material to reflect the doors and windows art characteristics of Ming and Qing Dynasties. The material itself also has its own language, through its contrast of old and new texture, the level of jewelry, different metal color processing color and inlaid other color rich material, it makes up for the lack of metal in color performance. This is used to show the color characteristics of the Ming and Qing Dynasties.

\subsection{The Cultural Connotation of Doors and Windows of Ming and Qing Dynasties Is Reflected in Jewelry}

The cultural significance contained behind the decoration of doors and windows is also people's yearning and hope for a better life. It is the cultural significance given to the doors and windows that makes it a representative of traditional culture. Animals in the traditional Chinese zodiac also often appear in doors and window patterns, such as chicken. "The ancients believed that darkness was the place where ghosts were hiding, and the golden rooster at sunrise became a god to reconcile Yin and Yang and expel ghosts" (Gu, 2007). And the chicken and "Ji (auspicious)" which are homophonic, can be used as an object of suppressing the house. From the historical extension and change of the decorative symbol "shape" and "meaning", it is not difficult to see that each change is not a complete denial of the previous one, but a new way of expression on its basis, so that it can be inherited and innovated. We will continue to continue this idea in the future design, and on the basis of refining and reconstructing the door and window art, we must continue to retain and inherit the traditional door and window art culture.

\section{Works Creation}

Around the beauty of form and artistic conception of doors and window art, combined with their own learning, using the changes of shape, structure, mate- 
rials and technology, respectively, the author created two works from the three aspects of formal beauty, artistic conception beauty and connotation of doors and windows, realizing the formal beauty and artistic conception beauty in jewelry. Visual viewing is the most basic requirement of jewelry. The use and collocation of a variety of jewelry materials and processes can enhance the artistic expression ability of jewelry. Combined with the previous exploration of artistic expression techniques, jewelry reflecting the traditional Chinese artistic conception was created. This personal creation plan uses three forms of expression: jewelry structure, color ornament and jewelry texture. Based on the law of formal beauty, the jewelry is reconstructed and decorated with different texture and colors.

\subsection{Work Autumn}

In Figure 4, from the perspective of different door and window perspectives, the branches are inserted into the boxes representing different perspectives to express that the same scenery is completely different from different people and from different angles. This jewelry selects doors and Windows as the main part, uses branches to break the rules of the door and window layout, uses the relationship between doors and Windows to present a sense of space and uses local electroplating to create a sense of hierarchy in the color of the work.

\subsection{Work Plum}

Figure 5 is inspired from the perspective of indoor outdoor scenery through doors and windows, aiming to show the artistic conception conveyed by the integration of scenery and doors and windows. Through the interpretation of the

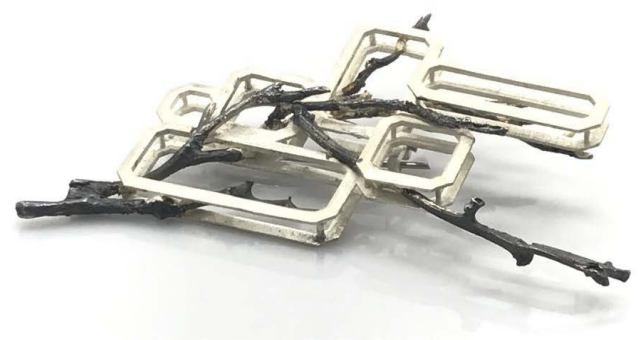

Figure 4. Autumn (photoed by the author, 2017).

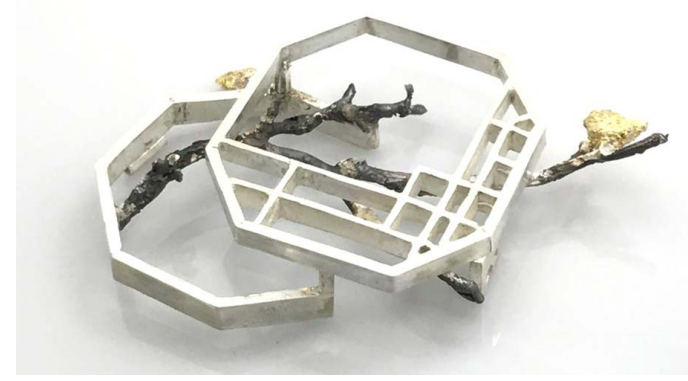

Figure 5. Plum (photoed by the author, 2017). 
relationship between the doors and windows and the owners in the Ming and Qing Dynasties, the personal preferences of the owners are integrated into the scenery, considered from the perspective of different owners, and the process of lost wax casting is used to show the texture of the branches and bamboo. At the same time, through making the old and electroplating technology to enrich the color of the jewelry, showing the characteristics and tension of the scenery.

\section{Conflicts of Interest}

The authors declare no conflicts of interest regarding the publication of this paper.

\section{References}

Crafts, L. (2007). 500 Earrings: New Directions in Contemporary Jewelry. Sterling Publishing, New York.

Gu, B. B. (2007). Study on "Door" and "Window" in Suzhou in Qing Dynasty. PhD Thesis, Tongji University, Shanghai.

Jiu, L. (2013).The Window Contains the Splendid Three Thousand Years of Ma Weidu. Ancient Chinese Doors and Windows, 21, 6.

Ren, J. (2011). Jewelry Design Foundation. China Construction Industry Press, Beijing.

Wen, R. Q. (2009). Chinese Ancient Doors and Windows Art and Packaging Design. Visual Innovation Design, 13, 7.

Yewn (2012). Window Flower Series. Barbara Jewelry, 23, 72. 